\title{
Postglacial colonization shows evidence for sympatric population splitting of Eurasian perch (Perca fluviatilis L.) in Lake Constance
}

\author{
J. BEHRMANN-GODEL,*G. GERLACH† and R. ECKMANN* \\ *Limnological Institute, University of Konstanz, 78457 Konstanz, Germany; †Marine Biological Laboratory, Woods Hole, MA 02543- \\ 1015, USA
}

\begin{abstract}
Previous microsatellite analysis showed that two subpopulations of perch (Percafluviatilis L.) exist in Lake Constance. This raises questions of whether (i) Lake Constance was colonized by two populations that diverged in allopatry, or (ii) the two subpopulations diverged in sympatry. Sequence analysis of a 365 bp mtDNA fragment (5'-end of the D-loop) of perch from Lake Constance and adjacent waters revealed 10 haplotypes. We suggest colonization via the Danube river, based on the frequency and dispersion of haplotypes, and knowledge of the lake's palaeohydrological development. Pairwise $F_{\mathrm{ST}}$-values using mitochondrial DNA sequences showed no significant population subdivision. Our study provides strong evidence that subpopulations of perch in Lake Constance have diverged in sympatry.
\end{abstract}

Keywords: control region, Europe, postglacial colonization, mtDNA, Perca fluviatilis L., sympatric differentiation

Received 4 June 2003; revision received 30 September 2003; accepted 5 November 2003

\section{Introduction}

Pleistocene glaciations not only widely formed today's landscapes, but also had major influences on patterns of animal dispersal and colonization (Avise 1992; Hewitt 1996, 2001; Bernatchez \& Wilson 1998; Taberlet et al. 1998). In Europe, wide areas of Scandinavia and the Alps were repeatedly covered by ice sheets during the Pleistocene glaciations. Glacial advances and retreats formed lakes and reorganized river channels and drainages. During the Pleistocene glaciations the Rhine glacier coming from the inner Alps excavated the deep pre-alpine Lake Constance. The earliest colonization of Lake Constance by fish may have taken place during the retreat of the most recent glacier 15000-10000 years ago. The rivers Rhine and Danube, which are the two nearest fluvial systems, are the most probable refugia for freshwater organisms for Lake Constance. These two rivers are already known as refugia for genetically different forms of a variety of freshwater

Correspondence: J. Behrmann-Godel. Fax: +49 753188 3533; E-mail: Jasminca.Behrmann@uni-konstanz.de fish species including Eurasian perch (Riffel \& Schreiber 1998; Nesbø et al. 1999; Gross et al. 2001; Weiss et al. 2002).

Our study focused on Eurasian perch (Perca fluviatilis L.) a widely distributed freshwater fish species, and the second most common species in Lake Constance. Previous microsatellite analysis had shown that perch in Lake Constance do not form a panmictic population but are subdivided into two genetically different subpopulations $\left(G_{\mathrm{ST}}=0.07\right)$. One population is found in the Upper Lake (population 1), which is deep, oligotrophic and warmmonomictic. The other population is found mainly in the Lower Lake (population 2), which is much shallower, mesotrophic and dimictic. Both lake basins are connected by a stretch of lotic habitat with no physical barriers separating the two populations, which means that they exist in sympatry (Gerlach et al. 2001). By sequencing mitochondrial DNA (mtDNA) we were able to use a phylogeographical approach to evaluate two alternative hypothesis: (i) Lake Constance had been colonized by two genetically different perch populations from different refugia, which have come into secondary contact postglacially; and (ii) the two subpopulations reflect genetic differences that have developed in sympatry after the postglacial colonization. 

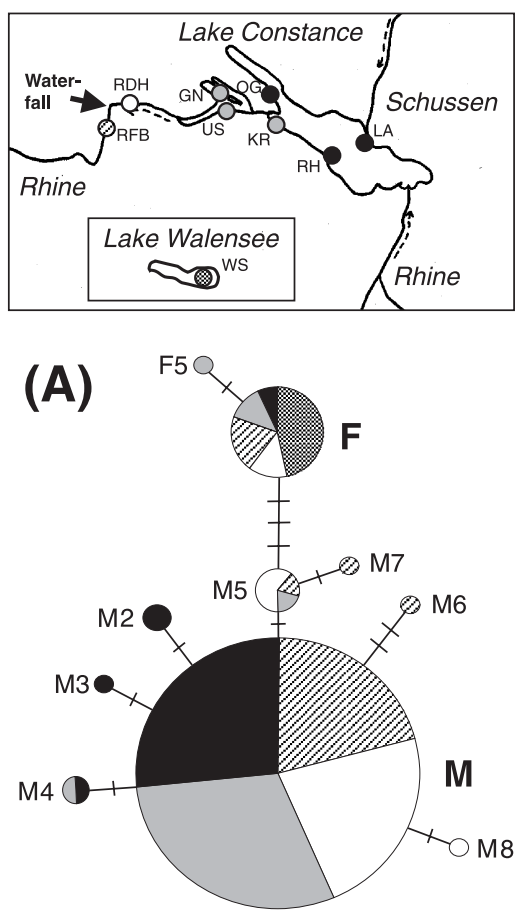

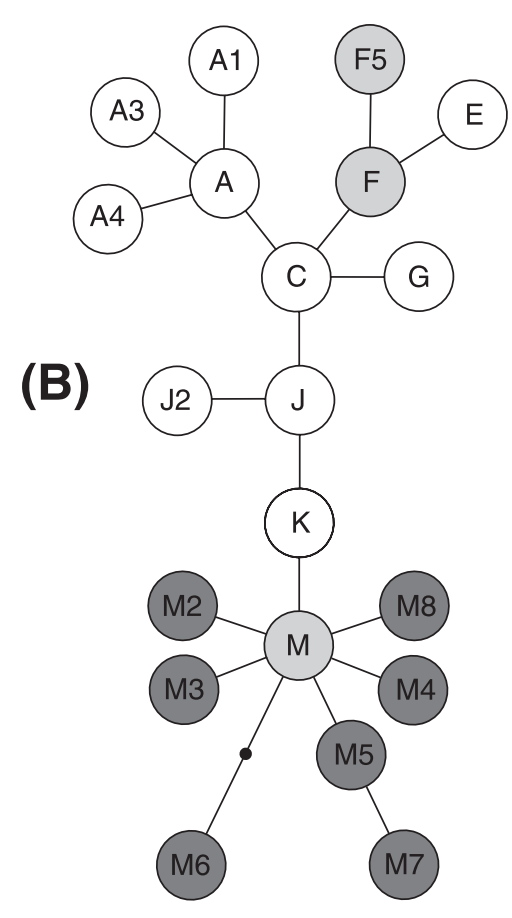

Fig. 1 Haplotype networks from mtDNA sequence data of Eurasian perch generated by statistical parsimony as implemented by TCS (v. 1.13; Clement et al. 2000). Haplotype designations refer to Nesbø et al. (1999) and this study. (A) Haplotype network for populations from Lake Constance, the two Rhenian localities and Lake Walensee. Black lines connect haplotypes, short bars reflect the number of mutational steps between haplotypes. Circle sizes represent haplotype frequencies, and fill patterns refer to geographical localities shown in the map. (B) Haplotype network from mtDNA sequence data of the study area, including the main haplotypes for Eurasian perch from Nesbø et al. (1999). Black lines connect haplotypes and represent a single mutational step. Dark grey circles represent haplotypes found in this study, white circles represent haplotypes found by Nesbø et al. (1999). Light grey circles represent haplotypes found in both studies, small black circles represent missing haplotypes.

\section{Materials and methods}

\section{Sampling, DNA extraction, amplification and sequencing}

Eighty-two perch were analysed for mtDNA D-loop sequence variation, corresponding to base $65-430$ of the $5^{\prime}$ end of the mtDNA control region in Eurasian perch (Accession no. 14724). DNA samples of perch from Lake Constance and Lake Walensee were the same as in Gerlach et al. (2001), except for localities LA and OG where three and seven new perch were caught. Additional perch were caught in the River Rhine, 17 upstream and 18 downstream of the waterfall (Fig. 1A). Muscle tissue was stored in $80 \%$ ethanol until DNA extraction. Genomic DNA was extracted according to standard salt extraction procedures (Sambrook et al. 1989). To amplify 365 bp of the mtDNA Dloop the primers HV2 and CSB-D (Nesbø et al. 1998a) were used under the published reaction conditions. Polymerase chain reaction (PCR) products were purified using the GFX PCR/DNA and Gel Band Purifications-kit (Amersham Biosciences Europe GmbH, Freiburg, Germany). The same primers were also used as sequencing primers, whereby single-strand sequencing was carried out for most individuals (using HV2 as sequencing primer). Double-strand sequencing was carried out for one individual of each haplotype (except haplotype T, using also CSB-D as sequencing primer). Sequencing was done by GATC (Biotech AG Konstanz, Germany), using an ABI 377 HT Automated Sequencer.

\section{Data analysis}

Alignment of mtDNA sequences was done by eye and a haplotype network was calculated using the computer program TCs (v. 1.13; Clement et al. 2000). TCS uses a cladogram estimation method, also known as statistical parsimony described by Templeton et al. (1992) to estimate gene genealogies from DNA sequences that differ by only a few mutational steps.

To analyse geographical population subdivision we calculated pairwise $F_{\mathrm{ST}}$ estimates using conventional $F$-statistics based on mtDNA haplotype frequencies with the software package ARLEQUIN (v. 2.0; Schneider et al. 2000). Significance of the estimates was determined by a $10000 \mathrm{step}, 1000$ iteration, Markov chain method.

\section{Results}

We found 10 different haplotypes based on 11 variable sites among Eurasian perch sampled at 9 different localities (see Appendix for haplotypes and their distribution among localities). The two main haplotypes $\mathrm{M}(n=53)$ and $\mathrm{F}$ $(n=15)$ were found in individuals from Lake Constance and the two Rhenian localities. Haplotypes M and F and one other haplotype F5 are identical to those described by Nesbø et al. (1999). In Lake Walensee and the two Rhenian localities sampled by Nesbø et al. (1999), the River Rhine and Lake Zürich, F was the sole haplotype found. The authors found the M-haplotype in the western part of the 
Danube but not in the Rhine, while the F-haplotype occurred in the southern part of the Rhine and in the Danube. The remaining eight haplotypes found in this study (F5 and M2-M8) were very rare and appeared only in one individual (except haplotypes M2 and M4 which appeared in two individuals and haplotype M5 which appeared in five individuals). Haplotypes M2-M8 seem to be unique to Lake Constance and the two nearby Rhenian localities and to date have not been found elsewhere in the European drainages sampled (Nesbø et al. 1998b, 1999; Refseth et al. 1998).

A haplotype network (Fig. 1A) demonstrates the relationships between the different haplotypes. The two main haplotypes $\mathrm{M}$ and $\mathrm{F}$ are separated by four mutational steps. Five of the seven newly found haplotypes differed from the common M-haplotype by one mutation, whereas M6 and M7 differed by two mutations.

If we include the main haplotypes found by Nesbø et al. (1999), all the missing nodes between haplotypes M and F are filled by other European populations. The newly found haplotypes all cluster with the $\mathrm{M}$ haplotype at the base of the haplotype cladogram (Fig. 1B).

Mitochondrial DNA pairwise $F_{\mathrm{ST}}$-values showed no significant differences between any of the six localities sampled within Lake Constance. When we combined the data of the three localities LA, OG and RH for subpopulation 1 , and KR, GN and US for subpopulation 2, the two subpopulations did not differ significantly. Similarly, there were no significant differences between any of the Lake Constance and the two Rhenian localities (Table 1). Thus, the population differentiation within Lake Constance, demonstrated by microsatellite analysis (Gerlach et al. 2001), could not be seen using mtDNA sequences. However based on our mtDNA data, the populations of Lake Constance and the two Rhenian localities were significantly different from the Lake Walensee/Lake Zürich population and from the population of the western part of the River Danube (Table 1).

\section{Discussion}

In contrast to the previous microsatellite analysis, showing that two subpopulations of Eurasian perch exist in sympatry in Lake Constance (Gerlach et al. 2001), no evidence for a similar population split could be detected by pairwise $F_{\mathrm{ST}}$-values of mtDNA haplotype sequences. If different mtDNA lineages have colonized the lake, the lack of differentiation today could be due to past hybridization and introgression. However, the two main haplotypes, F and M, might originate from colonization by two different mtDNA lineages, because the split between them is much older than the last glaciation (see Nesbø et al. 1999). In our opinion the existence of two genetically distinct subpopulations in Lake Constance has developed independently from the colonization of the lake by different mtDNA lineages and represents the result of sympatric differentiation. Similar conclusions were drawn by Douglas et al. (1999), who examined models of evolution for morphologically different forms of Coregonus from the Central Alpine region including three different forms from Lake Constance. Genetic diversity among populations of Coregonus was best explained by the species flock concept: repeated sympatric divergence of distinct populations, which occurred independently among these lakes, has lead to the evolution of multiple endemic forms.

In Lake Constance, the striking differences in morphology and associated differences in the trophic state of the two basins Upper Lake and Lower Lake could lead to differing selective forces acting on regional perch populations. Restricted gene flow due to philopatry, sexual selection or other behavioural mechanisms could then cause assortative mating, which will drive population splitting and may lead to sympatric speciation in the future (Dieckmann \& Doebeli 1999; Kondrashov \& Kondrashov 1999; Doebeli \& Dieckmann 2003).

Evidence for restricted gene flow and resulting population subdivision after colonization may also be seen at the mtDNA level because nearly all the derived haplotypes

Table 1 Pairwise $F_{\mathrm{ST}}$-values from mtDNA sequence data of Eurasian perch populations of Lake Constance (Population 1 and 2 ), the River Rhine (RFB, RDH, WS/ZS) and the western part of the River Danube (DN) calculated by ARLEQUIN. Significance values were determined by a 10000 step, 1000 iteration, Markov chain method

\begin{tabular}{|c|c|c|c|c|c|}
\hline & Population 1 & Population 2 & RFB (dw) & RDH (uw) & WS/ZSt (R. lakes) \\
\hline \multicolumn{6}{|l|}{ Population 1} \\
\hline Population 2 & -0.027 & & & & \\
\hline RFB (dw) & -0.011 & -0.026 & & & \\
\hline RDH (uw) & 0.006 & -0.014 & -0.034 & & \\
\hline WS/ZSt (R. lakes) & $0.745^{* * *}$ & $0.746^{* * *}$ & $0.664^{* * *}$ & $0.679 * * *$ & \\
\hline DNt & $0.231^{* *}$ & $0.219^{* *}$ & $0.121^{*}$ & $0.157^{* *}$ & $0.398^{* *}$ \\
\hline
\end{tabular}

$\mathrm{dw}$ : downstream of the waterfall; uw: upstream of the waterfall. R. lakes: Rhine, lakes Walensee (WS) and Zürichsee (ZS).

${ }^{*} P<0.05 ;{ }^{* *} P<0.01 ; * * *<0.001$.

tmtDNA data from Nesbø et al. (1999). 

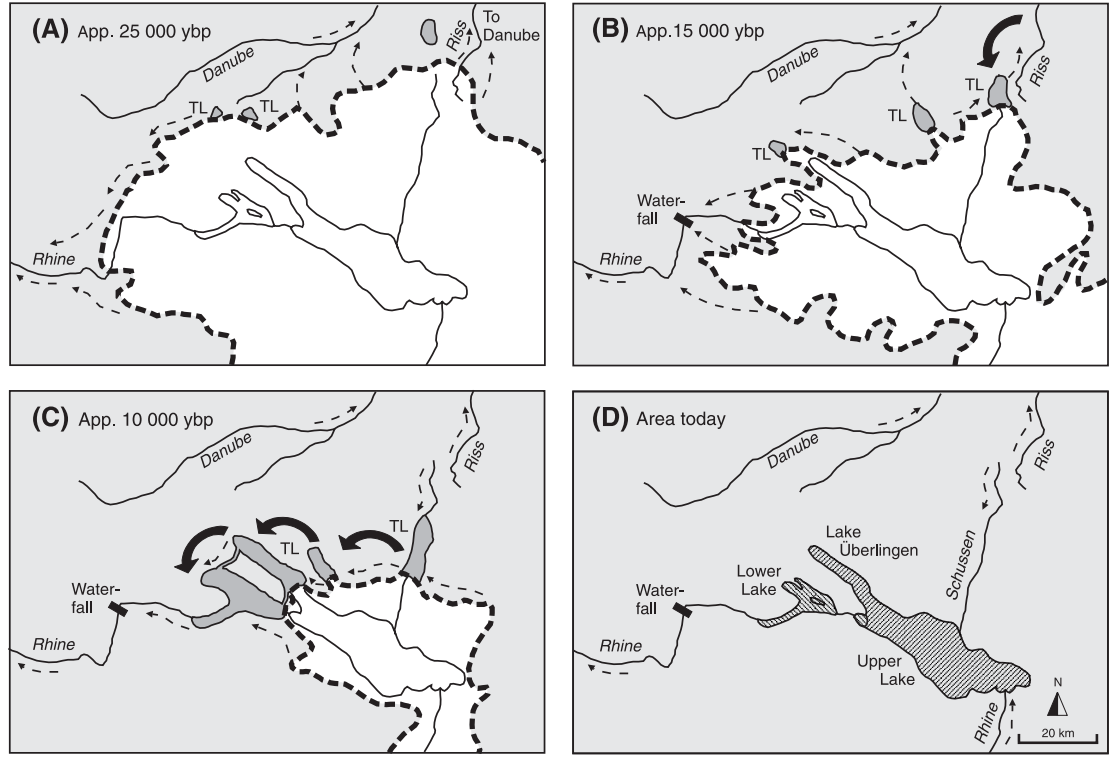

Fig. 2 Map of the drainage area of Lake Constance, simplified from Keller \& Krayss (2000) during and after the last (Würm) glaciation. Dashed arrows indicate directions of water flow. (A-C) Withdrawal of the glacier during three recessional stages. White area, glacier; TL, temporal proglacial lake; black arrows, hypothetical colonization route of Eurasian perch from the Danube system. (D) Lake Constance today. Hatched areas refer to subpopulations as revealed by microsatellite analysis (Gerlach et al. 2001). Forward slash, population 1, backward slash, population 2 .
(M2, M3, M6, M7 and M8) were found at only individual localities, whereas the ancestral M-haplotype was found at all localities. However, the question remains, whether the haplotypes derived from $\mathrm{M}$ (and $\mathrm{F}$ in one case) could have evolved during the very short time span of $\sim 15000$ years. Divergence rates of $6-7 \%$ for the $5^{\prime}$-end of the D-loop have been suggested for some perciform species such as cichlids (Meyer et al. 1990). Based on these estimates, a divergence rate of $7 \%$ could be sufficient to allow for the evolution of the derived haplotypes within the lake.

The most frequent mtDNA haplotype in this study was the M-haplotype, which was mainly found in the western part of the Danube (exceptions: one individual each in the rivers Tiber and Prut; Nesbø et al. 1999), where it cooccurs with the F-haplotype in a proportion of $\sim 50 \%$ each haplotype. Within Lake Constance, $75 \%$ of all individuals were of the M-haplotype whereas only three individuals $(7.5 \%)$ belonged to the F-haplotype (the remaining $17.5 \%$ belonged to the derived haplotypes M2-M8 and F5). Nesbø et al. (1999) hypothesized that the F-haplotype, which is $1 \%$ divergent from the M-haplotype, dispersed extensively in Western Europe and subsequently intergraded with the Danubian group. The strikingly different proportions of the two main haplotypes $\mathrm{M}$ and $\mathrm{F}$ in the Danube and within Lake Constance may reinforce this hypothesis and date the time of colonization of the Danube by the F-haplotype to late or post Pleistocene. In our scenario, Eurasian perch from a Danubian source population colonized Lake Constance during the last glacial retreat. Two different scenarios could then explain the low number of F-haplotypes within Lake Constance: (i) both haplotypes colonized the lake from the Danubian drainage at the same time, and the F-haplotype suffered selective dis- advantage that kept it at a low frequency. However, the Fhaplotype found in the lower Rhine and the upper Danube seems to have expanded from a more northern (not Danubian) refugium (Nesbø et al. 1999). Thus during colonization of Lake Constance perhaps only the M-haplotype was available, so that (ii) a Danubian population containing exclusively M-haplotypes colonized Lake Constance. The occurrence of the F-haplotype within Lake Constance would then reflect a more recent secondary colonization event. Another piece of evidence for a secondary colonization of the lake by the F-haplotype could be found in the difference of the amount of derived haplotypes. The star phylogeny of the M-haplotype (Fig. 1) with seven derived haplotypes would seem to imply extreme demographic expansion and dominance, whereas only one derived F-haplotype was found.

By contrast, colonization of Lake Constance by the Fhaplotype originating from a Rhenian source population is unlikely but cannot be excluded completely. Ever since all the melt water from the late Pleistocene glacier drained into the River Rhine, the water had (and has still) to pass a huge waterfall (Fig. 2). This natural barrier probably precluded perch from the Rhine drainage colonizing Lake Constance. Even a highly migratory fish species such as the Atlantic salmon (Salmo salar L.) was not able to overcome the waterfall and did not colonize Lake Constance.

Today, there is no connection between Lake Constance, which belongs to the Rhine drainage, and the Danube drainage. Thus the question remains how perch from the Danube could have colonized Lake Constance. During the Pleistocene glaciations, the entire region of the Alpine Rhine including Lake Constance was completely covered by a glacier (Fig. 2A-C). Geological data show that during 
deglaciation huge temporal proglacial lakes, which were connected to the Danube drainage system, existed in front of the glacier (Keller \& Krayss 2000). These temporal lakes could have been used by perch to colonize Lake Constance. Figure 2(A-C) shows a likely scenario of colonization by M-haplotypes from the Danube via one of these temporal lakes. As the glacier retreated, a drainage to the River Rhine became ice-free. From then on melt water drained west to the Rhine, and the connection to the Danube system was cut off. Following the melt water streams, perch could have reached the first ice-free basins of Lake Constance, Lake Überlingen and the Lower Lake which have never been completely isolated during the different recessional stages of glacier withdrawal (Fig. 2C).

One question, however, remains, why did the M-haplotype not colonize more downstream regions of the River Rhine. In our study, the M-haplotype was found in the same high proportion downstream of the waterfall as in Lake Constance itself (see Appendix). This might be explained by a passive transport of fish within the water column. But not one individual of the M-haplotype was found in the downstream parts of the Rhine drainage system (Nesbø et al. 1999 and this study). Very similar results were obtained for brown trout (Salmo trutta L.). Within the Danube drainage two mtDNA lineages, the Danubian and Atlantic lineage, were found (Osinov \& Bernatchez 1996; Bernatchez 2001; Weiss et al. 2001), whereas in the Rhine drainage only the Atlantic lineage occurred (Osinov \& Bernatchez 1996; Bernatchez 2001). For perch in the Rhine system, no physical barriers have existed since the last glaciation which might prevent the M-haplotype from expanding within the Rhine, once it is flushed down the waterfall. We suggest, following the arguments of Bernatchez (2001) for brown trout, that partial genetic incompatibilities of the haplotype lineages may have accumulated during their geographical isolation, which then limited introgressive hybridization between them. Furthermore, the M-haplotype as the later migrant, may have been unable to colonize habitats where the F-haplotype as the pioneer disperser was already established. Both factors may then have prevented the M-haplotype from colonizing the Rhine drainage system, a hypothesis that needs further testing.

\section{Acknowledgements}

The authors are very grateful to O. Keller for information and helpful discussions on the formation of Lake Constance during the Pleistocene, Kurt Egloff for help in obtaining fish samples, and Marta Barluenga and Walter Salzburger for their help in data analysis. We also thank Steven Weiss, Henri Persat and two unknown referees for their helpful comments on this manuscript. Funding was provided by Deutsche Forschungsgemeinschaft within the collaborative research centre SFB 454, Littoral of Lake Constance, and the cooperation program of the Swiss Kanton Thurgau and the University of Constance.

\section{References}

Avise JC (1992) Molecular population structure and the biogeographic history of a regional fauna. A case history with lessons for conservation biology. Oikos, 63, 62-76.

Bernatchez L (2001) The evolutionary history of brown trout (Salmo trutta L.) inferred from phylogeographic, nested clade, and mismatch analyses of mitochondrial DNA variation. Evolution, 55, 351-379.

Bernatchez L, Wilson CC (1998) Comparative phylogeography of Nearctic and Palearctic fishes. Molecular Ecology, 7, 431-452.

Clement M, Posada D, Crandall KA (2000) TCs: a computer program to estimate gene genealogies. Molecular Ecology, 9, 1657-1660.

Dieckmann U, Doebeli M (1999) On the origin of species by sympatric speciation. Nature, 400, 354-357.

Doebeli M, Dieckmann U (2003) Speciation along environmental gradients. Nature, 421, 259-264.

Douglas MR, Brunner PC, Bernatchez L (1999) Do assemblages of Coregonus (Teleostei: Salmoniformes) in the central alpine region of Europe represent species flocks? Molecular Ecology, 8, $589-603$.

Gerlach G, Schardt U, Eckmann R, Meyer A (2001) Kin-structured subpopulations in European perch (Perca fluviatilis L.). Heredity, 86, 213-221.

Gross R, Kuehn R, Baars M, Schroeder W, Stein H, Rottmann O (2001) Genetic differentiation of European grayling populations across the Main, Danube and Elbe drainages in Bavaria. Journal of Fish Biology, 58, 264-280.

Hewitt GM (1996) Some genetic consequences of ice ages, and their role in divergence and speciation. Biology Journal of the Linnean Society, 58, 247-276.

Hewitt GM (2001) Speciation, hybrid zones and phylogeography or seeing genes in space and time. Molecular Ecology, 10, 537-549.

Keller O, Krayss E (2000) Die Hydrographie des Bodenseeraums in Vergangenheit und Gegenwart. Berichte der St. Gallischen. Naturwissenschaftlichen Gesellschaft, 89, 39-56.

Kondrashov AS, Kondrashov FA (1999) Interactions among quantitative traits in the course of sympatric speciation. Nature, 400, 351-354.

Meyer A, Kocher TD, Basasibwaki P, Wilson AC (1990) Monophyletic origin of Lake Victoria cichlid fishes suggested by mitochondrial DNA sequences. Nature, 347, 550-553.

Nesbø CL, Arab MO, Jakobsen KS (1998a) Heteroplasmy, length and sequence variation in the mtDNA control regions of three percid fish species (Perca fluviatilis, Acerina cernua, Stizostedion lucioperca). Genetics, 148, 1907-1919.

Nesbø CL, Fossheim T, Vollestad LA, Jakobsen KS (1999) Genetic divergence and phylogeographic relationships among European perch (Perca fluviatilis) populations reflect glacial refugia and postglacial colonization. Molecular Ecology, 8, 1387-1404.

Nesbø CL, Magnhagen C, Jakobsen KS (1998b) Genetic differentiation among stationary and anadromous perch (Perca fluviatilis) in the Baltic Sea. Hereditas, 129, 241-249.

Osinov AG, Bernatchez L (1996) 'Atlantic' and 'Danube' phylogenetic groups of the sea trout Salmo trutta complex: genetic divergence, evolution, protection. Voprosy Ikhtiologii, 36, 762-786.

Refseth UH, Nesbø CL, Stacy JE, Voellestad LA, Fjeld E, Jakobsen KS (1998) Genetic evidence for different migration routes of freshwater fish into Norway revealed by analysis of current perch (Perca fluviatilis) populations in Scandinavia. Molecular Ecology, 7, 1015-1027. 
Riffel M, Schreiber A (1998) Morphometric differentiation in populations of the Central European sculpin Cottus gobio L., a fish with deeply divergent genetic lineages. Canadian Journal of Zoology, 76, 876-885.

Sambrook J, Fritsch EF, Maniatis T (1989) Molecular Cloning: A Laboratory Manual, 2nd edn. Cold Spring Harbor Laboratory Press, Cold Spring Harbor, NY.

Schneider S, Roessli D, Excoffier L (2000) ARLEQUIN, Version 2.000: A Software for Population Genetics Data Analysis. Genetics and Biometry Laboratory, University of Geneva, Switzerland.

Taberlet P, Fumagalli L, Wust-Saucy A-G, Cosson J-F (1998) Comparative phylogeography and postglacial colonization routes in Europe. Molecular Ecology, 7, 453-464.

Templeton AR, Crandall KA, Sing CF (1992) A cladistic analysis of phenotypic associations with haplotypes inferred from restriction endonuclease mapping and DNA sequence data. III. Cladogram estimation. Genetics, 132, 619-633.

Weiss S, Persat H, Eppe R, Schlötterer C, Uiblein F (2002) Complex patterns of colonization and refugia revealed for European grayling Thymallus thymallus, based on complete sequencing of the mitochondrial DNA control region. Molecular Ecology, 11, 1393-1407.

Weiss S, Schlötterer C, Waidbacher H, Jungwirth M (2001) Haplotype (mtDNA) diversity of brown trout Salmo trutta in tributaries of the Austrian Danube: massive introgression of Atlantic basin fish: by man or nature? Molecular Ecology, 10, 1241-1246.

This project is part of our research on population genetics, behaviour and competitive interactions with other species, of Eurasian perch in a large oligo- to mesotrophic prealpine lake. The study was carried out at the University of Constance as part of Jasminca Behrmann-Godel's PhD project. Gabriele Gerlach's research work focuses on population genetics to explain dispersal patterns and social structure in a variety of different species. Reiner Eckmann is a fish ecologist interested in the analysis of species interactions in littoral and pelagic habitats of large, oligotrophic lakes. 


\section{Appendix}

Sampling sites of perch (as shown in Fig. 1) and mtDNA haplotype distribution, including two Rhenian and one Danubian population from Nesbø et al. (1999)

\begin{tabular}{|c|c|c|c|}
\hline Population & Drainage & $N$ & Haplotypes $(n)$ \\
\hline LA pop1* & Rhine (L. Constance) & 7 & $\mathrm{~F}(1), \mathrm{M}(4), \mathrm{M} 2(2)$ \\
\hline OG pop1* & Rhine (L. Constance) & 6 & $M(6)$ \\
\hline RH pop $1^{*}$ & Rhine (L. Constance) & 6 & M (4), M3 (1), M4 (1) \\
\hline KR pop2* & Rhine (L. Constance) & 8 & F5 (1), M (6), M5 (1) \\
\hline GN pop2* & Rhine (L. Constance) & 6 & $\mathrm{~F}(1), \mathrm{M}(5)$ \\
\hline US pop2* & Rhine (L. Constance) & 7 & $\mathrm{~F}(1), \mathrm{M}(5), \mathrm{M} 4(1)$ \\
\hline RFB & Rhine $(\mathrm{dw}) \ddagger$ & 18 & $\mathrm{~F}(3), \mathrm{M}(12), \mathrm{M} 5$ (1), M6 (1), M7 (1) \\
\hline $\mathrm{RDH}$ & Rhine (uw) $\ddagger$ & 17 & $\mathrm{~F}(2), \mathrm{M}(11), \mathrm{M} 5$ (3), M8 (1) \\
\hline WS & Rhine (L. Walensee) & 7 & $F(7)$ \\
\hline L. Züricht & Rhine (L. Zürich) & 10 & F 10 \\
\hline Rhine R.† & Rhine (France) & 7 & $\mathrm{~F}(7)$ \\
\hline Danube R.t & Danube (Austria) & 20 & F 11, M (9) \\
\hline
\end{tabular}

*pop $1 / 2$ refer to genetically distinct perch subpopulations in Lake Constance as shown by a microsatellite analysis with five loci (Gerlach et al. 2001).

tmtDNA data from Nesbø et al. (1999).

$\ddagger(\mathrm{dw})$, downstream of the waterfall; (uw), upstream of the waterfall. 